Tomasz Dziurzyński

\title{
AN INTEGRATED MODEL OF WATER EROSION OF SOILS IN A WATERSHED
}

A review of the erosion models to date indicates that we lack nowadays a simple method for calculating erosion, both in the form of rubble output and the determination of spatial intensity of soil erosion in a watershed (de Roo, 1993). An attempt of application of an integrated model of water erosion of soils in a watershed is presented in the paper.

\section{THE AREA OF STUDY}

The work to date concerning problems of soil erosion has been conducted primarily in the upland and mountainous areas, in view of the high intensity of respective processes in these areas. Few studies dealing with lowland areas have been reported. In the present paper we deal with the assessment of erosion of soils in the lowland basin of Olszanka, a partial catchment area of the upper Wilga, a confluent of Vistula to the South of Warsaw. The basin in question has the surface of 24 sq.km the length of the main water flow is $9.6 \mathrm{~km}$, and its slope is $2.2 \%$. The slope of the area of the basin exceeds $10 \%$ in only few places (attaining $13 \%$ at maximum). The primary crops are cereals and root crops, forests take $16 \%$ of total surface, while permanent grasslands - approximately $4 \%$.

The surface materials, which make up the basin of Olszanka, originate primarily from the middle-Polish glacial periods, and have the thickness of some $35 \mathrm{~m}$. Boulder clays and fluvioglacial sands dominate here. In the bottom of the valley the Holocene sediments, gravel and sand alluvia, in places interlaced with silts, prevail. In the upper parts of the area clays are turning sandy and so sandy material dominates on the surface, taking most often the form of medium sand, light clayey sand, and strong clayey sand. Pseudo-podzolic soils dominate (taking 38\% of the catchment area), accompanied by brown leached and podzolic soils. These soils were formed primarily on the sandy bedding. 
THE METHOD

It is proposed that for the calculation of the material eroded and transported away from the drainage basin two kinds of models be applied with the point and the spatially distributed parameters. This allows not only for the analysis of the effect of the erosion process in the form of the material transported in the closing profile, but also for consideration of the spatial distribution of its intensity. The model is divided into three parts: hydrological, sedimentological, and the erosion oriented. The first two parts constitute the portions of the sediment graph model, while the third one is a separate subsystem based upon the Universal Soil Loss Equation (USLE), whose parameters are determined in the particular, homogeneous areas of the watershed. Precipitation constitutes the input to all the subsystems of the model. In the first two parts it is necessary to determine the histogram of effective precipitation, and in the third one - of total precipitation. The output is constituted by the hydrograph of direct outflow, flood sediment graph, as well as the volume of eroded material in the basin and its spatial differentiation.

An additional element of the model is constituted by the part concerning the hysteresis of throughflow and the concentration of the transported rubble. This allows for identification of the sources of material transported in the closing profile (Klein, 1984). The hysteresis shape can be determined through application of the sediment graph model. The scheme of the model is shown in Fig. 1.

The sediment graph model is based upon the instantaneous unit sediment graph (IUSG) and the modified equation of soil loss (MUSLE). It was for the first time presented by Williams (1978). IUSG was defined similarly to the instantaneous unit hydrograph (IUH) as the temporal distribution of the rubble load being the effect of an instantaneous precipitation event.

The IUSG is obtained from the product of the IUH ordinates and the function of concentration of the transported rubble $c(t)$. This subject was taken up in Poland by Banasik (1994, 1994a). He presented the analytical form of the IUSG. Using the equation describing the ordinates of IUH according to the model of Nash (Soczyńska, 1993) he obtained the formula for the ordinates of the instantaneous unit sediment graph. The characteristics of IUSG were determined and the relations necessary for calculating model parameters were provided.

Production of the rubble in the consecutive time intervals can be determined in an analogy to the determination of the effective precipitation, from equation (1):

$$
\Delta Y_{j}=Y_{j}-Y_{j-1} \text { for } j=1,2,3, \ldots n
$$

where: $Y_{j}$ is the mass of the rubble produced between the beginning of the precipitation event and the end of the time interval $j(\mathrm{Mg})$, and $n$ is the number of time intervals of duration of a rainfall. 


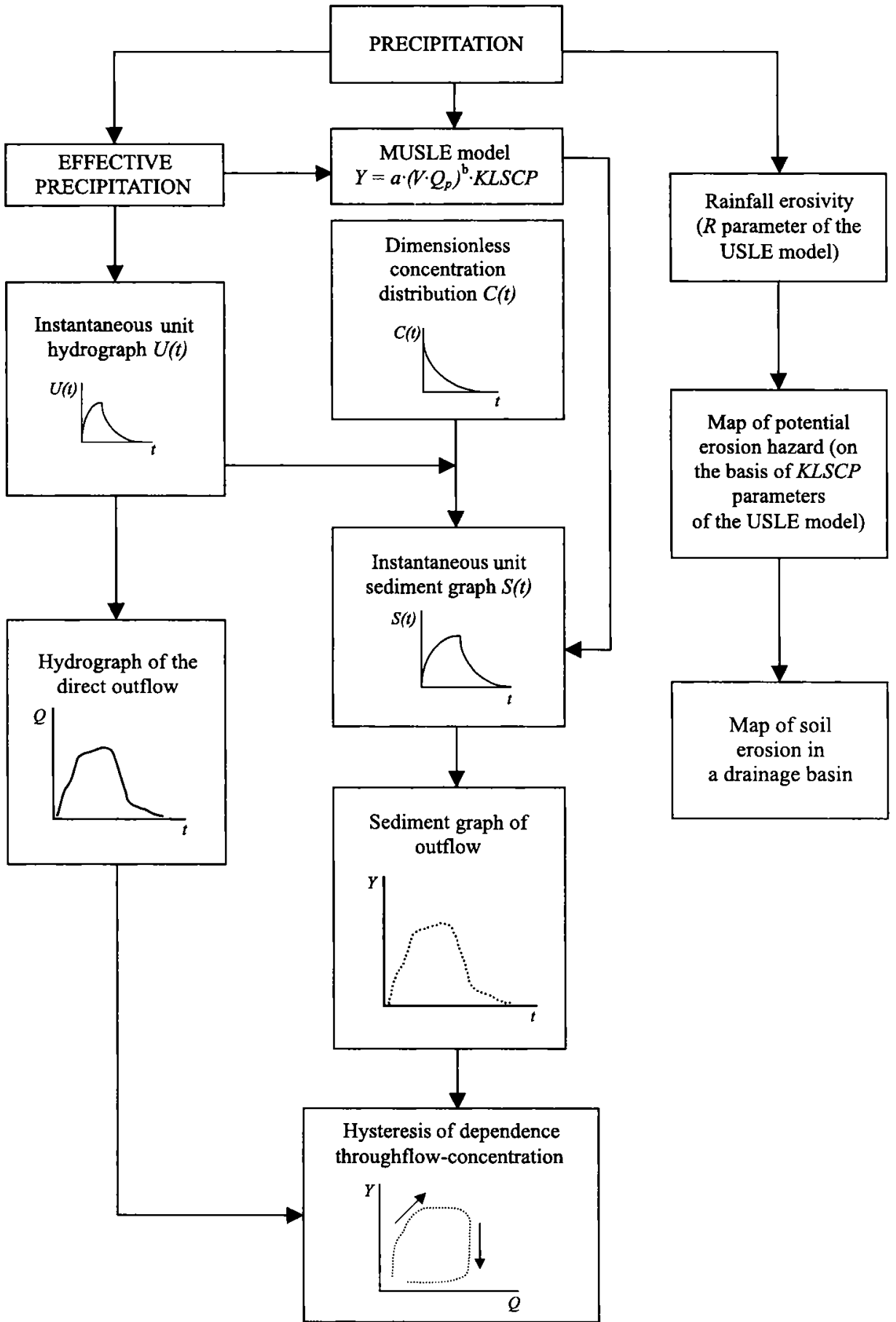

Fig. 1. A scheme of the integrated model of soil erosion in a watershed. 
Total mass of the rubble formed during one swelling may be calculated according to the MUSLE formula of Williams (1975). The model input is constituted by the variable calculated according to the equation defined on the basis of 39 occurrences of precipitation - runoff - rubble output, registered in a small watershed in South England (Banasik, Walling, 1996).

When applying the sediment graph model it was first necessary to select the best runoff models, which would be used for further work. The measurements carried out by the present author in the years 1998 and 1999, as well as the data from the archives of the Institute of Meteorology and Water Management (IMGW), were the basis for verification of the models. Data from altogether eleven swellings were acquired. The models verified were those of Wackermann (see Thiele and Euler, 1981), of Nash in the version of Lutz (Lutz, 1984), and GIUH in the version of IMGW (Ostrowski, 1986, 1990). Optimisation of the parameters of the Wackermann's model for the drainage basin analysed, and so the values of the IUH parameters obtained, were different from those used to date. The model was referred to as "Wackermann UW". The results of verification are shown in Table 1.

Table 1.

The correlation coefficient $[R]$, the determination coefficient $\left[R^{2}\right]$,

and the total square error [CBK] were calculated for the ordinates of the measured and the model-defined hydrographs

\begin{tabular}{|l|c|c|c|c|}
\hline Agreement measures & Lutz & Wackermann & Wackermann UW & IMGW \\
\hline $\mathrm{R}$ & 0.89 & 0.59 & 0.85 & 0.23 \\
$\mathrm{R}^{2}$ & 0.79 & 0.36 & 0.73 & 0.06 \\
$\mathrm{CBK}$ & 6.00 & 9.82 & 5.67 & 20.81 \\
\hline
\end{tabular}

For further analysis the model of Nash in the version by Lutz and the two versions of the Wackermann's model were taken. Application of the sediment graph model for the assumptions given by Williams (1978) required calculation of IUSG using IUH in the Wackermann's version. Equation (2) below was applied, which allowed to reduce the surface area under the function $S(t)$ to unity, see Ozga-Zieliński, Brzeziński (1994):

$$
S(t)=\frac{u(t) \cdot c(t)}{\int_{0}^{\infty} u(t) \cdot c(t) d t}
$$

where: $S(t)$ are the ordinates of IUSG $\left[\mathrm{g} / \mathrm{s} \cdot \mathrm{mm}^{2}\right], u(t)$ - ordinates of IUH $\left[\mathrm{m}^{3} / \mathrm{s} \cdot \mathrm{mm}\right], \mathrm{c}(\mathrm{t})$ - ordinates of the function of rubble intensity $\left[\mathrm{g} / \mathrm{m}^{3} \cdot \mathrm{mm}\right.$.

After substituting in the place of $u(t)$ the equation defining the ordinates of IUH after Wackermann, the resolution of the integral, and simplification, the formula (3) was obtained, defining the ordinates of the instantaneous unit sediment graph: 


$$
S(t)=\frac{\exp (-B t)\left[\beta t K_{1}^{2} \exp \left(-t K_{1}^{-1}\right)+(1-\beta) t K_{2}^{2} \exp \left(-t K_{2}^{-1}\right)\right]}{\beta K_{1}^{2}\left(K_{1}^{-1}+B\right)^{-2}+{K_{2}^{2}}^{2}(1-\beta)\left({K_{2}}^{1}+B\right)^{-2}}
$$

where: $S(t)$ denotes the ordinates of the instantaneous unit sediment graph $\left(\mathrm{h}^{-1}\right), B$ - the parameter of the rubble transport $\left(\mathrm{h}^{-1}\right), \beta, K_{1}, K_{2}$ are the parameters of the Wackermann's model, $t$ - time (h).

The above equation contains four parameters: $\beta, K_{1}, K_{2}, B$. Three of them are, however, dependent uniquely upon the length of the main water flow and its slope. A precise topographical map suffices to determine them. The value of parameter $B$ can be determined on the basis of measurement data by minimising the difference between the observed and model-determined sediment graph. It is also possible to make use of the interdependence between the $L A G_{s}$ and $L A G$ characteristics (i.e. the so-called delay times).

Having measurements on the precipitation - runoff - rubble setting we can determine the $L A G_{s}$ and $L A G$ characteristics and their ratio. This ratio was equal for the drainage basin of Olszanka to 0.69 . Having this information we can make the value of $B$ dependent upon it. As a consequence of determination of the first statistical moments the following relation was obtained:

$$
\begin{gathered}
\frac{L A G_{s}}{L A G}=\left[\left(\beta K_{1}+(1-\beta) K_{2}\right) \cdot\left(\beta K_{1}^{-2}\left(K_{1}^{-1}+B\right)^{-2}+(1-\beta) K_{2}^{-2}\left(K_{2}^{-1}+B\right)^{-2}\right)\right]^{-1} . \\
\cdot\left[\frac{\beta K_{1}^{2}}{\left(B+K_{1}^{1}\right)^{3}}+\frac{(1-\beta) K_{2}^{-2}}{\left(B+K_{2}^{-1}\right)^{3}}\right]
\end{gathered}
$$

where: $L A G$ - average time in which effective precipitation reaches the profile closing the drainage basin (the lag time); $L A G_{s}$ - the average lag time for the rubble produced by the precipitation; $\beta, K_{1}, K_{2}$ - parameters of the Wackermann model; $B$ - transport parameter $\left(\mathrm{h}^{-1}\right)$.

The only unknown parameter in equation (4) is $B$, which can be calculated by introducing the values of all the remaining parameters and trying to satisfy the equality condition. Thereby a new equation is implicitly obtained and solved, relating the value of the transport parameter to the ratio of time lags and two physical characteristics of the drainage basin.

By applying two variants of values of the Wackermann model parameters the values of $B=0.031$ (for the Wackermann UW version) and $B=0.045$ (for the original version of the model having the parameters given by Thiele and Euler, 1981) were obtained. These two values were thereafter adopted for calculations.

In the years 1998 and 1999, simultaneously with the registration of throughflow, measurements were being made of clouding. Samples were taken with the bottle batometer, and the volume of rubble was determined with the tile-and-weight method. Data from seven precipitation - runoff - transported rubble episodes were gathered. The results of verification are shown in Table 2. 
The correlation coefficient $(R)$, the determination coefficient $\left(R^{2}\right)$,

and the total square error (CBK) were calculated for the ordinates of the measured and model-defined hydrographs

\begin{tabular}{|l|r|c|c|}
\hline Agreement measure & Lutz & Wackermann & Wackermann UW \\
\hline $\mathrm{R}$ & 0.80 & 0.68 & 0.74 \\
$\mathrm{R}^{2}$ & 0.65 & 0.47 & 0.56 \\
CBK $(\%)$ & 10.24 & 10.36 & 8.64 \\
\hline
\end{tabular}

In the study of the problem of erosion on the scale of a watershed essential information can be provided by the hysteresis loop of throughflow - rubble, since it brings information on the sources of the material transported in the water flow (Klein, 1984).

The sediment graph model allows to calculate the hysteresis loop in the uncontrolled drainage basin, since its output defines the load of transported material $(\mathrm{kg} / \mathrm{s})$. In order to calculate concentration one should divide the output value by the value of throughflow intensity, corresponding to it in a given instance, known either from measurement or from the outflow model applied previously. In order to minimise the number of elements calculated from the model and thus also to increase the reliability of results, total measured throughflow was taken in for calculations. In this manner seven hysteresis loops were analysed obtained from the measurement data, compared then with the ones calculated from the model, with application of the same agreement measures as in the case of sediment graph. The results are shown in Table 3.

Table 3.

Results of verification of the hysteresis loops - measured and calculated from the model

\begin{tabular}{|l|c|c|c|}
\hline Agreement measure & Lutz & Wackermann & Wackermann UW \\
\hline $\mathrm{R}$ & 0.66 & 0.58 & 0.58 \\
$\mathrm{R}^{2}$ & 0.44 & 0.34 & 0.34 \\
$\mathrm{CBK}$ & 13.57 & 14.29 & 8.78 \\
\hline
\end{tabular}

All the dependencies measured of the type throughflow - transported rubble were reflected in the right-hand-side loops, which may constitute a demonstration of a "close" origin of the transported rubble with respect to the closing profile. In conditions of a lowland basin with a broad valley bottom one can draw therefrom the conclusion that the material transported in the closing profile originates mainly from the erosion of a small fraction accumulated in the riverbed during the low flow periods.

Application of the third subsystem - the spatial differentiation of erosion - required elaboration of digital maps on the basis of which it would be possible to determine the values of parameters of the USLE equation. In elaboration of these maps use was made of a topographical and a soil 
map, aerial photography, and information from field charting. Vector maps of surface material, soils, slopes and land use were made using the GIS technology. The quasi-homogeneous fields were determined, in which the product of the KLSCP parameters was calculated, multiplied thereafter by the value of the eroding force of individual rainfalls $\left(R_{i}\right)$. Spatial distribution of soil erosion in the basin was obtained therefrom as the output.

The USLE model was verified on the basis of field studies carried out in the years 1998 and 1999. Measurement gutters of own construction were installed on selected slopes, meant to gather the material moving down the slopes. Every 30 days, on the average, the material was dried and weighted, and the analysis of pluviographical strips allowed to determine the eroding force of rains during the measurement period $\left(R_{i}\right)$. After determination of the remaining parameters of the model and calculation of erosion the result was compared with the measured value (see Fig. 2). Measurements from thirteen measurement sites were made use of.

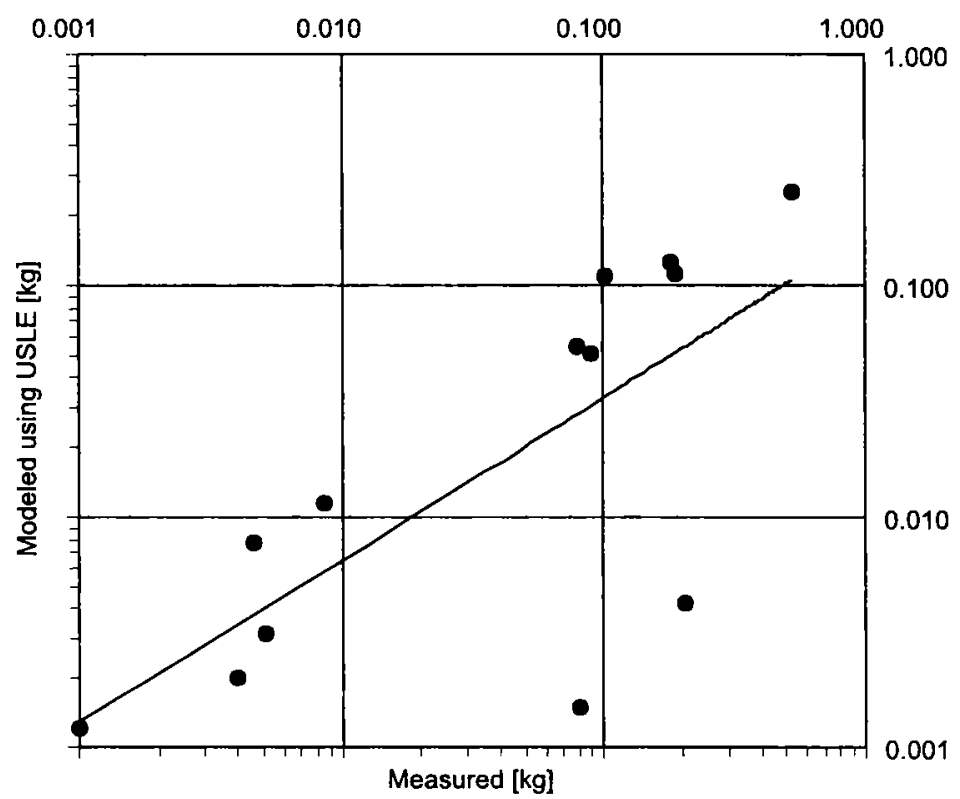

Fig. 2. The volume of eroded soil calculated from the USLE model as compared to the measured values.

In verification of the USLE model the three previously referred to statistical measures were used, namely $R, R^{2}$ and CBK. The values of coefficients of correlation and determination were, respectively, 0.88 and 0.77 , while the value of CBK was $24.55 \%$. The results obtained were particularly influenced by two measurements made in the period between June $24^{\text {th }}$ and July $28^{\text {th }}, 1998$, in the potato and maize field. The rain, which occurred 
during this period had a very small eroding force and barely fulfilled the boundary conditions of the method. Yet, it was decided to apply the equation for these two measurements, since the measured values of erosion were significant. It turned out that the rain of a theoretically small eroding force can cause soil fluction and erosion, depending upon the instantaneous and local conditions, which cannot be reflected through the USLE model. The threshold condition formulated by the authors of the method for the eroding rains is that they be of at least $12.7 \mathrm{~mm}$. Further, a rainfall is not considered eroding if it is separated by more than six hours without rain or with rain of less than $1.3 \mathrm{~mm}$. Rainfall of a thinner corresponding layer is considered eroding only when its maximum intensity attains at least $6.35 \mathrm{~mm}$ per 15 minutes. Besides the measurement material used for verification of the model the present author had the possibility of observing rainfalls which would not satisfy these criteria and yet did cause fluction and erosion.

The model with spatially distributed parameters indicated the areas of the highest intensity of erosion. They were constituted by the fields used for root crops, having slopes of more than $3.5^{\circ}$. The lowest values of erosion were obtained for the areas covered by forest or meadows, irrespective of its slope.

The maps of the spatial distribution of soil erosion provided, in particular, the information on the amounts of material eroded in the drainage basin during the individual precipitation episodes, which could be compared with the measured rubble mass flowing away from the watershed. A comparison of these values for six swellings is shown in Fig. 3.

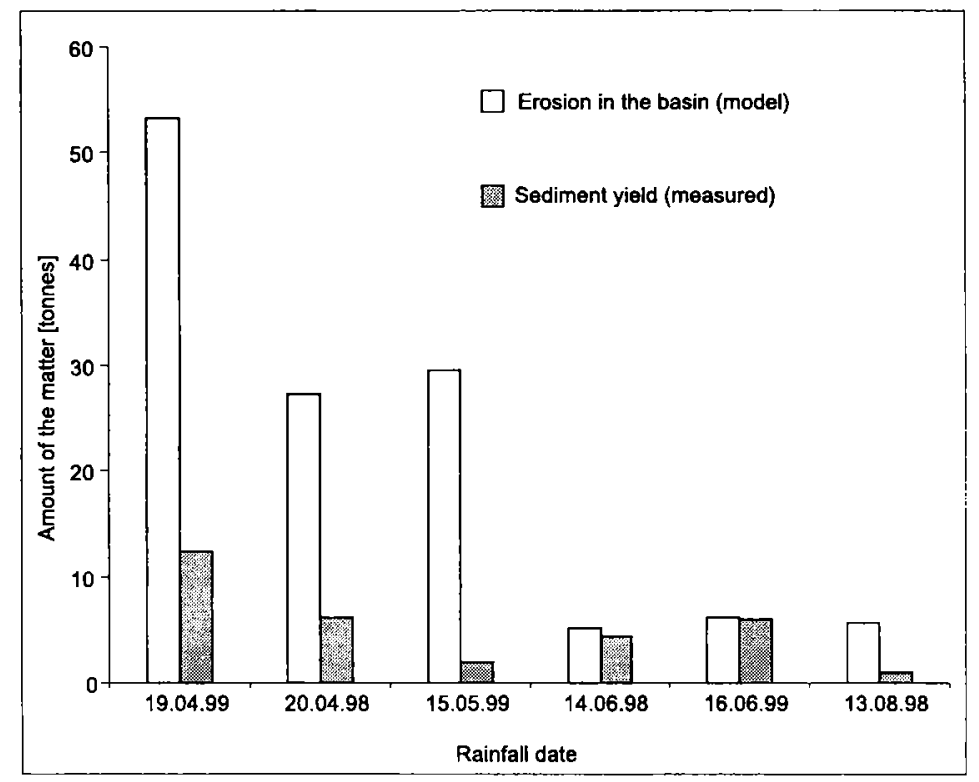

Fig. 3. A comparison of the modelled volume of soil erosion in a watershed with the measured rubble output in a profile (Gózdek) during the selected rainfall episodes. 


\section{CONCLUSIONS}

The models of outflow taken in for verification were characterised by a significant variability of results. The best results were obtained using the model of Lutz and the Wackermann UW model (i.e. the one with the parameters optimised for the drainage basin analysed). When the original form of the parameters of the Wackermann model was applied, the hydrographs obtained as output would always be ahead, in terms of time, of the measured waves. The GIUH model of IMGW did not give satisfying results.

The new version of the instantaneous unit sediment graph, presented here, is simpler than the one used to date, and it makes the shape of IUSG dependent upon the two physical parameters of the drainage basin and the transport parameter $(B)$.

The value of $B$ can be calculated on the basis of the relation (4), which involves the ratio of lag times of the fluction of the matter $\left(L A G_{s}\right)$ and the outflow ( $L A G$ ), and the three constants depending upon the two physical parameters of the basin, whose values can be determined using a detailed topographical map.

In the course of verification, the here presented version of the IUSG model gave satisfactory results, comparable to the ones obtained with the application of the previous version of the model.

The in-field measurements and the analysis of the hysteresis loop of the throughflow - transported rubble characteristics indicate that in the conditions of a lowland drainage basin, similar to that of Olszanka, the rubble transported in the water flow during swelling may originate primarily from the river bed and the areas adjacent to it (the escarpments and undercuts). The proposed model of the sediment graph can be applied in the determination of the hysteresis loop of the throughflow and the intensity of transported rubble in the watersheds, which are uncontrolled with respect to the runoff of the transported material.

The USLE formula, verified on the basis of experimental studies of erosion, carried out with the help of gutters of own construction, gave satisfactory results. Yet, the threshold conditions adopted for the eroding rains, seem to apply to rainfalls of significant volume or intensity as compared to those measured in the drainage basin of Olszanka. Even a rainfall not satisfying the conditions stipulated by the authors of the method can bring about a relatively important erosion.

In the comparison of the amount of material eroded in the whole of the basin during a rainfall with the rubble output in the closing profile during a swelling caused by this rainfall, much higher values of erosion than the output were obtained in the spring months and only slightly higher in the final period of spring and in summer. The differentiation of the rubble output in the spring and summer swellings was not that distinct.

Further studies in the domain of modelling of soil erosion and rubble transport in a flow ought to concern the model of sediment graph (including 
the value of parameter $B$ ) in other basins, and the determination of transported rubble in lowland flows. It would be essential for the verification of the USLE model, both on the scale a slope and of a whole drainage basin, to define the length of surface runoff and the distance over which the matter originating from the soil erosion is transported.

\section{REFERENCES}

B a n a sik K., 1994, Model sedymentogramu wezbrania opadowego w matej zlewni rolniczej [A model of sediment graph of a rainfall swelling in a small agricultural watershed], Wydawnictwo SGGW, 191, Warszawa.

B an a sik K., 1994a, Determination of watershed LAG times in rainfall-runoff-sediment yield investigations, Prace Naukowe Instytutu Geotechniki i Hydrotechniki Politechniki Wrocławskiej, 67.

B a n a sik K., W alling D.E., 1996, Predicting Sedimentographs for a Small Agricultural Catchment, Nordic Hydrology, 27(4), 275-294.

De Roo A.P.J., 1993, Modelling Surface Runoff and Soil Erosion in Catchment Using Geographical Information Systems, Nederlandse Geografische Studies, 157.

Gerlach T., 1966, Współczesny rozwój stoków w dorzeczu górnego Grajcarka (Beskid Wysoki-Karpaty Zachodnie) [Contemporary development of slopes in the basin of upper Grajcarek stream (High Beskid-Western Carpathians)], Prace Geograficzne IG PAN, 52.

Kle in M., 1984, Anticlockwise Hysteresis in Suspended Sediment Concentration During Individual Storms, Catena, vol. 11, 251-257, Braunschweig.

Lut z W., 1984, Berechnung von Hochwasseradflussen unter Anwendung von Gebietkenngrössen, Mitteilungen IHW, 24, Karlsruhe.

Os trow ski J., 1990, A Rainfall-Runoff Model for Small Ungauged Watersheds in Polish Conditions, IAHS Publ., 191.

O z ga - Zi e li ńs k a M., B r ze z ińs ki J., 1994, Hydrologia stosowana [Applied Hydrology], Wyd. Naukowe PWN, Warszawa.

Soczyńsk a U. (ed.), 1993, Podstawy Hydrologii Dynamicznej, [Foundations of Dynamic Hydrology], Wyd. Uniwersytetu Warszawskiego, Warszawa.

Th i e le F., Euler G., 1981, Vergleichende Untersuchung zur Ermittlung von Übertragungsfunktionen aus Einzugsgebietsgrössen nach verschiedenen Methoden, Untersuchung für den DVWK-FA Niederschlag-Abflussmodelle.

Will i a m s J.R., 1978, A Sediment Graph Model Based on an Instantaneous Unit Sediment Graph, Water Resources Research, 14, 4, 659-664.

W ill i a m s J.R., 1975, Sediment Yield Prediction with Universal Equation Using Energy Factor, [in:] Present and Prospective Technology for Predicting Sediment Yield and Sources. Proc. Sediment Yield Workshop, ARS-40, USDA Sedimentation Lab., Oxford, Miss. 